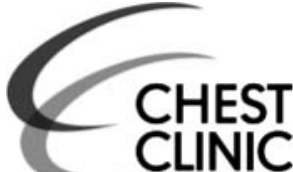

MRC and Asthma-UK Centre for Allergic Mechanisms in Asthma, King's College London, London, UK

\section{Correspondence to}

Dr Catherine M Hawrylowicz, Department of Asthma, Allergy and Respiratory Science, 5th

Floor Tower Wing, Guy's Hospital, King's College London, London SE1 9RT, UK; catherine.hawrylowicz@kcl.ac.uk

Received 20 June 2012 Accepted 2 August 2012 Published Online First 30 August 2012

\title{
Vitamin D and lung disease
}

\author{
Paul E Pfeffer, Catherine M Hawrylowicz
}

\section{ABSTRACT}

The classic role of vitamin $D$ in the regulation of calcium and phosphate metabolism, and its effects on bone health, are well established. More recently a critical role in immunity and respiratory health has been proposed. This arises from evidence for the capacity to generate the active metabolite, 1 $\alpha, 25$-dihydroxyvitamin D3 $(1,25(\mathrm{OH}) \mathrm{D} 3)$, locally in many tissues beyond the kidney; expression of the vitamin $\mathrm{D}$ receptor (VDR) in immune and structural cells not involved in calcium-phosphate homeostasis; and control by 1,25(OH)D3 of the transcription of genes associated with numerous different biological processes through its nuclear VDR.

Abnormalities in the vitamin $\mathrm{D}$ axis, including a high prevalence of vitamin $D$ insufficiency worldwide, now appear important in a wide range of pulmonary diseases including viral and bacterial respiratory infection, asthma, chronic obstructive pulmonary disease, and cancer. Actions of vitamin $D$ on innate immune responses, for example, production of antimicrobial peptides and autophagy, and on adaptive immune responses, for example, promoting regulatory lymphocytes, are believed to underpin these associations.

The principal source of vitamin $D$ is sunlight; solar ultraviolet $\mathrm{B}$ radiation converts 7-dehydrocholesterol in the skin to pre-vitamin D3-our environment, lifestyle and our genes greatly influence the efficacy of this pathway. Dietary intake of vitamin $\mathrm{D}$ is limited (figure 1). Although rickets and osteomalacia occur with vitamin D deficiency (circulating levels of 25-hydroxyvitamin $\mathrm{D}<25 \mathrm{nmol} /$ litre, although there is no consensus for the absolute cut-off value), evidence is accumulating of disease associations that occur in vitamin $\mathrm{D}$ insufficiency ( $<75 \mathrm{nmol} /$ litre). ${ }^{1}$ Importantly, vitamin D insufficiency is surprisingly common, with reports that the majority of adults in the UK are vitamin D insufficient year round. ${ }^{2}$

Asthma, chronic obstructive pulmonary disease (COPD), interstitial lung disease and cystic fibrosis show correlations between severity and low vitamin $\mathrm{D}$ status, as does incidence of pulmonary infections and lung cancer. ${ }^{3}{ }^{4}$ For example, paediatric studies in Costa Rica, North America and the UK have found associations between asthma exacerbations and vitamin D insufficiency. Although issues of confounding and reverse causation are problematic to these studies, gene studies and mechanistic science strongly support the role of vitamin D in pulmonary health. For example, polymorphisms in the vitamin $\mathrm{D}$ receptor (VDR) gene are associated with lower respiratory tract infections and severe respiratory syncytial virus bronchiolitis in children. ${ }^{4}$ In addition, levels and polymorphisms of vitamin D binding protein are associated with COPD. ${ }^{5}$

\section{MECHANISMS OF ACTION OF PULMONARY VITAMIN D}

The bronchial epithelium and immune cells can convert the circulating precursor 25-dihydroxyvitamin D3 $(25(\mathrm{OH}) \mathrm{D} 3)$ to local active $1,25(\mathrm{OH}) \mathrm{D} 3 .^{14}$ This and other parameters within the vitamin $\mathrm{D}$ axis (eg, cytochrome P450 27 (CYP27), CYP24) are modulated in response to diverse stimuli including cytokines, and toll-like receptor (TLR) ligands such as mycobacterial lipopeptides (TLR1/2L) and viral dsRNA (TLR3L).

$1,25(\mathrm{OH}) \mathrm{D} 3$ reduces production of inflammatory cytokines (such as interleukin-8 (IL-8)) and chemokines (such as leucocyte attracting CXCL10) from stimulated epithelial cells by modulating the nuclear factor $\kappa \mathrm{B}$ axis. ${ }^{4}{ }^{6}$ Although the reduction in inflammatory cytokines might be expected to lead to an impaired antimicrobial response, cell culture experiments actually show a maintained or strengthened antimicrobial response in the presence of vitamin $\mathrm{D}$ (see below). Other pathways in parenchymal cells regulated by vitamin $\mathrm{D}$ include cell proliferation and differentiation. For example, vitamin D can inhibit proliferation of airway smooth muscle and many pathways implicated in airway remodelling, such as matrix metalloproteases. ${ }^{7}$ Regulation of cell proliferation by vitamin $\mathrm{D}$ appears important in prevention and treatment of cancers.

A profound number of genes in leucocytes are affected by $1,25(\mathrm{OH}) \mathrm{D} 3 .^{8}$ Vitamin $\mathrm{D}$ promotes innate immune responses essential for the early protection against pathogens. This includes enhancing the synthesis of antimicrobial peptides such as cathelicidin and other vitamin $\mathrm{D}$ regulated molecules with antibacterial, antimycobacterial and antiviral actions. ${ }^{4}$ Vitamin $\mathrm{D}$ promotes autophagy, the cellular digestion of intracellular macromolecules and inclusions, in parenchymal and mononuclear immune cells. ${ }^{9}$ Autophagy is vital for cellular survival in the face of metabolic stress but is also important in clearing intracellular microbes such as mycobacteria, viruses and atypical pathogens. Autophagy also has an important function in killing neoplastic cells.

Vitamin D reduces expression of costimulatory molecules that are necessary for positive T-cell receptor signalling, and pro-inflammatory cytokines (eg, IL-12) by antigen-presenting cells, reducing their ability to promote adaptive immune responses. ${ }^{8}$ It promotes a tolerogenic dendritic cell phenotype with increased dendritic cell production of anti-inflammatory IL-10.

Vitamin D also regulates adaptive lymphocyte responses, inhibiting lymphocyte proliferation and cytokine production in pro-inflammatory $\mathrm{T}$ helper 1 (Th1) and Th17 responses, ${ }^{8}$ and enhancing FoxP3+ 


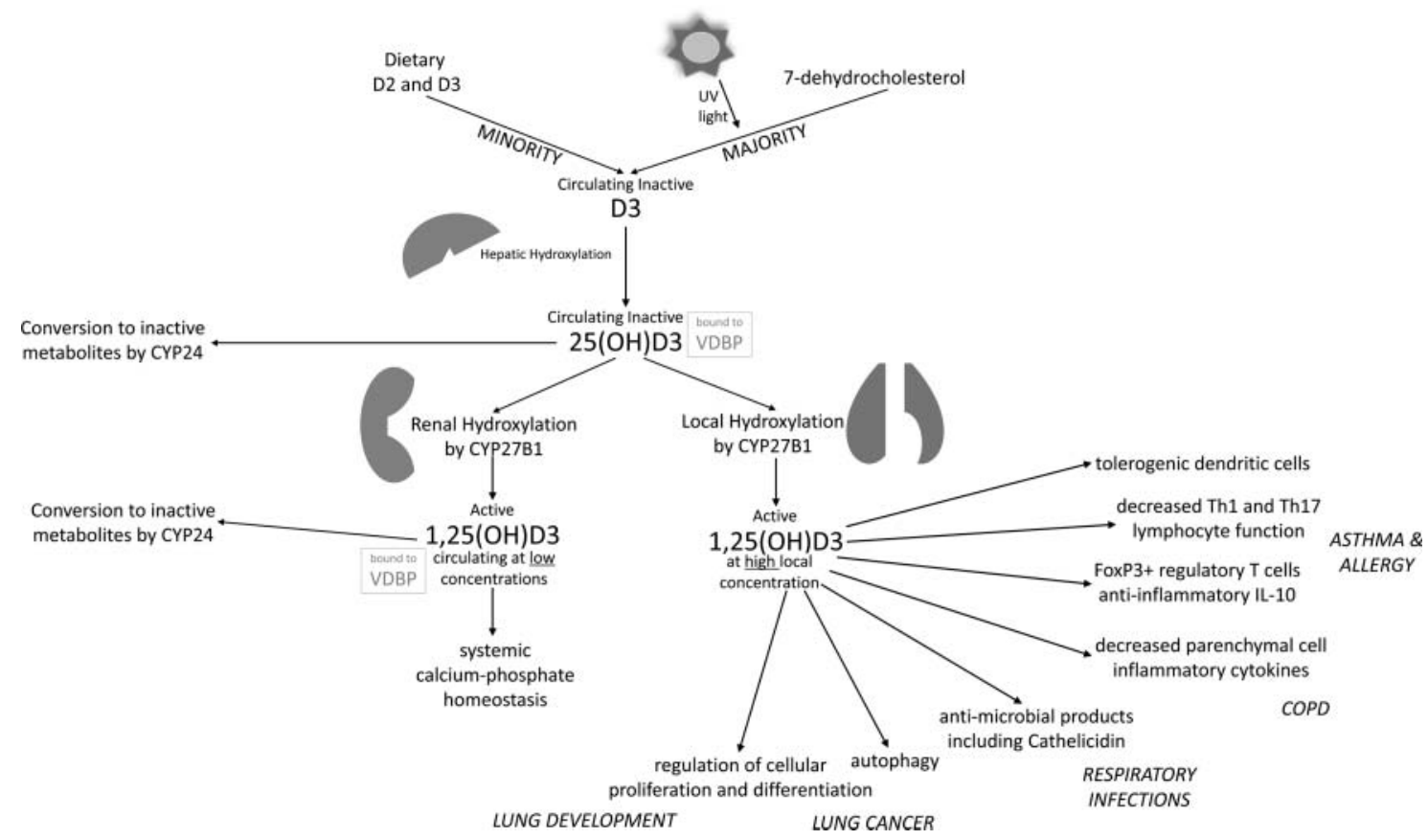

Figure 1 Schematic of vitamin $D$ axis and example functions of $1 \alpha, 25$-dihydroxyvitamin $D 3(1,25(\mathrm{OH}) \mathrm{D} 3)$ locally produced in the lungs. Diseases to which these functions may be relevant are given in italics. COPD, chronic obstructive pulmonary disease; CYP, cytochrome P450; Th, T helper; UV, ultraviolet.

regulatory T-cell (T-reg) responses and T-cell production of IL-10. Translational research has shown that vitamin $\mathrm{D}$ treatment is able to restore ex vivo steroid sensitivity in T cells from people with steroid-refractory asthma, and these data compliment increasing evidence for associations of low vitamin D status with poor asthma control. ${ }^{10}$ Interactions between lymphocytes and other cells, necessary for coordinated balanced immune responses, are also regulated by vitamin $\mathrm{D}$ - for example lymphocyte expression of CD200. ${ }^{11}$

This scientific evidence supports a profound role of vitamin $\mathrm{D}$ in orchestrating immune responses. Rising levels of local $1,25(\mathrm{OH}) \mathrm{D} 3$ during the immune response to a bronchial infection will boost innate immune responses and then regulate adaptive responses to prevent an excessive response. Mechanistically vitamin D insufficiency is thought to lead to more severe exacerbations in asthma and COPD as a result of an impaired innate response to the pathogen followed by an excessive adaptive immune response with increased production of inflammatory cytokines and increased bronchial inflammation.

\section{INTERVENTION AND THE FUTURE}

Research is now moving into large intervention studies examining the role of patient supplementation of vitamin D to treat diseases and also maternal/early life supplementation to prevent development of pulmonary diseases, for example the Vitamin D Antenatal Asthma Reduction Trial (VDAART) study investigating whether maternal supplementation in pregnancy may reduce the incidence of asthma and allergic illness. However, several issues need to be considered in these studies. It is unknown whether there may be continual improvement in disease activity with any increase in vitamin $\mathrm{D}$ levels upon patient supplementation (continual effect), or whether there will only be improvement in patients whose low vitamin $\mathrm{D}$ levels are elevated by supplementation over a threshold level (threshold effect). Different VDR polymorphisms strongly affect vitamin D action and may affect whether supplementation is beneficial. For example, Martineau et al showed that vitamin D supplementation of patients with tuberculosis reduced the time for sputum conversion, although this was only significant in patients with the tt TaqI polymorphism of the VDR gene. ${ }^{12}$ Bolus versus steady-state vitamin $\mathrm{D}$ supplementation, and the form of vitamin $\mathrm{D}$ supplement may also be important. Importantly, the low dose of vitamin D in over-the-counter supplements and in calcium supplements for preventing osteoporosis is much lower than the dose used in current trials.

Future vitamin $\mathrm{D}$ therapies for cancer, infection and asthma show great promise, although the forms of treatment and specific subgroups of patients who will respond are still being clarified through ongoing research.

Acknowledgements PP is the recipient of a fellowship and $\mathrm{CH}$ acknowledges financial support from the Department of Health via the NIHR comprehensive Biomedical Research Centre award to Guy's and St Thomas' NHS Foundation Trust in partnership with King's College London.

Contributors The authors contributed equally to this article.

\section{Competing interests None.}

Provenance and peer review Commissioned; internally peer reviewed.

\section{REFERENCES}

1. Holick MF. Vitamin D deficiency. N Engl J Med 2007;357:266-81.

2. Hypponen E, Power C. Hypovitaminosis D in British adults at age $45 \mathrm{y}$ : nationwide cohort study of dietary and lifestyle predictors. Am J Clin Nutr 2007;85:860-8.

3. Finklea JD, Grossmann RE, Tangpricha V. Vitamin D and chronic lung disease: a review of molecular mechanisms and clinical studies. Adv Nutr 2011:2:244-53.

4. Beard JA, Bearden A, Striker R. Vitamin D and the anti-viral state. J Clin Virol 2011;50:194-200.

5. Wood AM, Bassford C, Webster D, et al. Vitamin D-binding protein contributes to COPD by activation of alveolar macrophages. Thorax 2011;66:205-10.

6. Hansdottir S, Monick MM, Lovan N, et al. Vitamin D decreases respiratory syncytial virus induction of NF-kappaB-linked chemokines and cytokines in airway epithelium while maintaining the antiviral state. J Immunol 2010;184:965-74.

7. Banerjee A, Panettieri R Jr. Vitamin D modulates airway smooth muscle function in COPD. Curr Opin Pharmacol 2012;12:266-74. 
8. Khoo AL, Chai L, Koenen H, et al. Translating the role of vitamin D3 in infectious diseases. Crit Rev Microbiol 2012;38:122-35.

9. Hoyer-Hansen M, Nordbrandt SP, Jaattela M. Autophagy as a basis for the health-promoting effects of vitamin D. Trends Mol Med 2010;16:295-302.

10. Xystrakis E, Kusumakar S, Boswell S, et al. Reversing the defective induction of IL-10-secreting regulatory T cells in glucocorticoid-resistant asthma patients. $J$ Clin Invest 2006;116:146-55.
11. Dimeloe S, Richards D, Urry Z, et al. 1 1 ,25-Dihydroxyvitamin D3 promotes CD200 expression by human peripheral and airway-resident T cells. Thorax

2012;67:574-81.

12. Martineau AR, Timms PM, Bothamley GH, et al. High-dose vitamin D(3) during intensive-phase antimicrobial treatment of pulmonary tuberculosis: a double-blind randomised controlled trial. Lancet 2011;377:242-50. 